\title{
Regulation of Neuregulin Expression in the Injured Rat Brain and Cultured Astrocytes
}

\author{
Yoshihito Tokita, ${ }^{1}$ Hiroomi Keino, ${ }^{1}$ Fumiko Matsui, ${ }^{1}$ Sachiko Aono, ${ }^{1}$ Hiroshi Ishiguro, ${ }^{2}$ Shigeki Higashiyama, ${ }^{3}$ \\ and Atsuhiko Oohira ${ }^{1}$ \\ ${ }^{1}$ Department of Perinatology, Institute for Developmental Research, Kasugai, Aichi 480-0392, Japan, 2Institute for \\ Comprehensive Medical Science, Fujita Health University, Toyoake, Aichi 470-1192, Japan, and ${ }^{3}$ Department of \\ Biochemistry, School of Allied Health Science, Osaka University Medical School, Suita, Osaka 565-0871, Japan
}

In this report, we investigated whether reactive astrocytes produce neuregulins (glial growth factor 2/heregulin/acetylcholine receptor-inducing activity or neu differentiation factor) and its putative receptors, ErbB2 and ErbB3 tyrosine kinases, in the injured CNS in vivo. Significant immunoreactivities with antineuregulin, anti-ErbB2, and anti-ErbB3 antibodies were detected on astrocytes at the injured site $4 \mathrm{~d}$ after injury to the adult rat cerebral cortex. To elucidate the mechanisms for the upregulation of neuregulin expression in astrocytes, primary cultured astrocytes were treated with certain reagents, including forskolin, that are known to elevate the intracellular level of cAMP and induce marked morphological changes in astrocytes. Western blot analysis showed that the expression of a 52 $\mathrm{kDa}$ membrane-spanning form of a neuregulin protein was enhanced in cultured astrocytes after administration of forsko-

Reactive astrocytes are thought to support neuronal regeneration by secreting various growth factors and neurotrophic factors, such as basic fibroblast growth factor (bFGF) (Finklestein et al., 1988; Frautschy et al., 1991), transforming growth factor- $\beta 1$ (TGF- $\beta 1$ ) (Lindholm et al., 1992), pleiotrophin (Yeh et al., 1998), ciliary neurotrophic factor (CNTF) (Ip et al., 1993), nerve growth factor, brain-derived neurotrophic factor (Rudge et al., 1995), and neurotrophin 4 (Condorelli et al., 1994). After brain injury, all of these factors increase and take part in the cellular processes of wound healing.

Neuregulins are a class of cell surface and secreted proteins with diverse functions in a variety of different tissues (Peles et al., 1993). These factors have been isolated from a number of different cell types, and many different proteins are known to be generated from a single gene as alternative splicing variants (Marchionni et al., 1993). The widespread distribution of these factors in developing and mature nervous systems is consistent with evidence for the variety of neuregulin actions (Chen et al., 1994; Meyer and Birchmeier, 1994; Corfas et al., 1995; Jo et al., 1995). Several different types of glial cells have been shown to be supported in their growth and differentiation by neuregulins. One

\footnotetext{
Received Feb. 3, 2000; revised Dec. 4, 2000; accepted Dec. 11, 2000.

This work was supported in part by research grants from the Ministry of Education, Science, Culture, and Sports of Japan (Y.T., H.K., S.A., A.O.), from the Nissan Science Foundation (Y.T.), and from the Telmo Life Science Foundation (Y.T.). We thank Sachiko Kawashima for technical assistance.

Correspondence should be addressed to Yoshihito Tokita, Department of Perinatology, Institute for Developmental Research, Kasugai, Aichi, 480-0392 Japan. E-mail: tokita@inst-hsc.pref.aichi.jp.

Copyright (C) 2001 Society for Neuroscience $\quad 0270-6474 / 01 / 211257-08 \$ 15.00 / 0$
}

lin. The upregulation of glial fibrillary acidic protein was also observed in astrocytes treated with forskolin. In contrast, inactivation of protein kinase $\mathrm{C}$ because of chronic treatment with phorbol ester 12-O-tetradecanoyl phorbol 13-acetate downregulated the expression of the $52 \mathrm{kDa}$ isoform, although other splice variants with apparent molecular sizes of 65 and $60 \mathrm{kDa}$ were upregulated. These results suggest that the enhancement of neuregulin expression at injured sites is induced, at least in part, by elevation in intracellular cAMP levels and/or a protein kinase C signaling pathway. The neuregulin expressed on reactive astrocytes may stimulate their proliferation and support the survival of neurons surrounding cortical brain wounds in vivo.

Key words: neuregulin; ErbB2; ErbB3; forskolin; astrocyte; trauma; protein kinase $A$

of these neuregulins, glial growth factor 2 was initially identified because of its mitogenic activity on Schwann cells. Neuregulins have also been shown to promote astrocyte survival and differentiation in cerebral cortical dissociated cell cultures (PinkasKramarski et al., 1994) and to inhibit the differentiation and lineage commitment of oligodendrocyte progenitor cells (Vartanian et al., 1994; Canoll et al., 1996; Shi et al., 1998). In an earlier stage of neural development, neuregulins promoted glial differentiation and inhibited neuronal differentiation in cultured neural crest stem cells (Shah et al., 1996). In addition to their effects on glial differentiation, neuregulins are capable of promoting the synaptic maturation of both the peripheral nervous system (PNS) (Falls et al., 1993; Jo et al., 1995; Sandrock et al., 1995) and CNS (Ozaki et al., 1997; Yang et al., 1998) as well as promoting neuronal cell survival and neurite outgrowth (Bermingham-McDonogh et al., 1996).

Neuregulins have been shown to play an important role in pathological responses in the PNS. For example, neuregulin expression increased in Schwann cells during Wallerian degeneration (Carroll et al., 1997). These previous reports suggest that neuregulins also support neuronal cell survival and neuronal network reconstruction to repair the damaged CNS. However, it is unknown whether the expression of neuregulins increases after brain injury, and if so, what molecular events lead to induction.

In this report, we provide evidence to support the idea that reactive astrocytes produce neuregulins and their putative receptors, ErbB2 and ErbB3, after brain injury in vivo. We explored the regulatory mechanisms of neuregulin expression in astrocytes and found that both the levels of intracellular cAMP and protein 
kinase $\mathrm{C}(\mathrm{PKC})$ signaling pathways were involved in the regulation of neuregulin expression in vitro.

\section{MATERIALS AND METHODS}

Materials. Forskolin, DMEM, fetal calf serum (FCS), N6,2'-O-dibutyryladenosine $3^{\prime}, 5^{\prime}$-cyclic monophosphate (dB-cAMP); 8-bromoadenosine $3^{\prime}, 5^{\prime}$-cAMP (8Br-cAMP), and phorbol ester [12-O-tetradecanoyl phorbol 13-acetate (TPA)] were obtained from Sigma (St. Louis, MO). Penicillin and streptomycin solutions were obtained from Life Technologies (Gaithersburg, MD). We used human recombinant epidermal growth factor (EGF) (Austral Biologicals, San Ramon, CA), human recombinant bFGF (Peprotech, Rocky Hill, NJ), and human recombinant platelet-derived growth factor (PDGF) (Life Technologies) in the present experiment. A rabbit antibody against human neuregulin, which recognizes both $\alpha$ and $\beta$ neuregulins (Neo Markers, Union City, CA), a goat antibody against human neuregulin- $\beta$ (Santa Cruz Biotechnology, Santa Cruz, CA), a rabbit anti-bovine glial fibrillary acidic protein (GFAP) antibody (Dako, Glostrup, Denmark), a mouse monoclonal anti-human ErbB2 antibody, a rabbit anti-human ErbB3 antibody (Transduction Laboratories, Lexington, KY), fluorescein-conjugated antimouse IgG and anti-goat IgG (Vector Laboratories, Burlingame, CA), and Cy3-conjugated streptavidin (Jackson ImmunoResearch, West Grove, PA) were used.

Brain lesions and immunohistochemistry. The treatment of animals was performed according to the ethical rules of our institution. Anesthetized adult Sprague Dawley rats (8-weeks-old) were used. An anteroposterior surgical incision (5-mm-long, 2-mm-deep, and 1-mm-wide) was made by inserting a microknife into the cortex. After $4 \mathrm{~d}$, the rats were deeply anesthetized and perfused with $4 \%$ paraformaldehyde in PBS. Brains were removed and stored for $5-7 \mathrm{~d}$ in $4 \%$ paraformaldehyde in PBS. Serial $50-\mu \mathrm{m}$-thick vibratome sections were preincubated in a blocking solution (1\% normal horse serum, $1 \%$ BSA, and $0.01 \%$ Triton X-100 in PBS) for $1 \mathrm{hr}$ after a $5 \mathrm{~min}$ incubation in 1\% hydrogen peroxide in PBS to inactivate endogenous peroxidase activity. The sections were incubated in the blocking solution containing (in $\mu \mathrm{g} / \mathrm{ml}$ ): 0.5 antineuregulin- $\beta, 0.5$ anti-ErbB2, or 0.5 anti-ErbB3 antibodies for 2 or $3 \mathrm{~d}$ at $4^{\circ} \mathrm{C}$ and were then subjected to immunohistochemical analysis using the avidin-biotin peroxidase technique [Vectastain avidin-biotin complex (ABC) elite kit; Vector Laboratories] with diaminobenzidine tetrahydrochloride as a color development reagent. For immunohistochemical control experiments, the anti-neuregulin- $\beta$ antibody was used after absorption with the recombinant extracellular domain of neuregulin- $\beta$ (Neo Markers). Because anti-ErbB2 and anti-ErbB3 antibodies were raised against a part of the extracellular domains of the receptors, these antibodies were also used, after absorption with the extracellular domains of the corresponding receptors, for the control experiments. Each antibody $(0.25 \mu \mathrm{g})$ was mixed with or without a corresponding recombinant protein $(25 \mu \mathrm{g})$ in $0.5 \mathrm{ml}$ of a blocking solution for $1 \mathrm{hr}$ for neutralization. The extracellular domains of the ErbB2 and ErbB3 used were expressed as fusion proteins with an $\mathrm{Ig}-\mathrm{Fc}$ region by Chinese hamster ovary $(\mathrm{CHO})$ cells, using the method described by Higashiyama et al. (1997).

Colocalization of GFAP with neuregulin and the ErbB2 protein on astrocytes was determined by costaining with a rabbit anti-GFAP antibody $(1: 2000)$ and a mouse monoclonal anti-ErbB2 antibody $(0.5 \mu \mathrm{g} / \mathrm{ml})$ or a goat anti-neuregulin antibody $(0.5 \mu \mathrm{g} / \mathrm{ml})$, followed by a biotinylated anti-goat $\operatorname{IgG}(1: 200)$ or biotinylated anti-mouse $\operatorname{IgG}(1: 200)$ as the secondary antibody. Immunoreactivity was visualized by fluoresceinconjugated anti-rabbit $\operatorname{IgG}(1: 200)$ and Cy3-conjugated streptavidin (1: 2000). The ErbB3 protein on the ErbB2-positive astrocytes was detected by double-staining with a rabbit anti-ErbB3 antibody and a mouse monoclonal anti-ErbB2 antibody. Immunoreactivity for ErbB3 was visualized by $\mathrm{Cy} 3$-conjugated goat anti-rabbit IgG, and immunoreactivity for ErbB2 was visualized by treatment with biotinylated anti-mouse IgG (1:200) followed by Alexa Fluor 488-conjugated streptavidin (Molecular Probes, Eugene, OR) (1:100). For display figures, merged color images were processed using Adobe Photoshop (Adobe Systems, San Jose, CA).

Primary astrocyte culture. Primary astrocyte cultures were done according to the procedures described by Miller et al. (1995) with minor modifications. In brief, the neocortexes of Sprague Dawley rats on embryonic days 17 and 18 were dissected, treated with trypsin $(0.1 \%)$, dissociated by trituration, and plated at a density of $5 \times 10^{7}$ cells per 75 $\mathrm{cm}^{2}$ flask in DMEM (adjusted to $\mathrm{pH} 7.5$ with $25 \mathrm{~mm}$ HEPES and 14.3 mM $\mathrm{NaHCO}_{3}$ ) supplemented with $10 \%$ FCS, $1 \mathrm{~mm}$ pyruvate, $2 \mathrm{~mm}$ glutamine, $50 \mu \mathrm{g} / \mathrm{ml}$ streptomycin, and $50 \mathrm{U} / \mathrm{ml}$ penicillin. Cells were maintained in DMEM containing 10\% FCS for $6 \mathrm{~d}$. Next, the flasks were shaken mechanically at $200 \mathrm{rpm}$ overnight in a horizontal orbital shaker to remove the top layer of cells. This procedure removed most of the oligodendrocytes, microglia, and type 2 astrocytes and thus yielded mainly type- 1 astrocytes with a flat shape (Jensen and Chiu, 1990). One day after this purification step, secondary astrocyte cultures were established by trypsinizing the primary culture and subplating it onto poly-Dlysine-precoated plastic dishes in DMEM supplemented with 10\% FCS.

Treatment of cultured astrocytes with exogenous factors. Within 10-14 d in culture, the astrocytes had formed a subconfluent monolayer. The culture medium was exchanged with fresh DMEM containing 10\% FCS. To investigate the effects of cAMP on neuregulin and GFAP synthesis, the following reagents were added to the culture media, and the cultures were maintained at $37^{\circ} \mathrm{C}$ for $3 \mathrm{hr}$ : forskolin $(0.1-30 \mu \mathrm{M})$, dB-cAMP (1 $\mathrm{mM})$, and 8Br-cAMP (1 mM). Growth factors and phorbol ester (TPA) were also added to fresh DMEM containing 1\% FCS to investigate their effects on the synthesis and shedding of neuregulins. The cultures were maintained at $37^{\circ} \mathrm{C}$ for $24 \mathrm{hr}$ with the following concentrations of each factor: $10 \mathrm{ng} / \mathrm{ml}$ EGF, $10 \mathrm{ng} / \mathrm{ml}$ PDGF, $10 \mathrm{ng} / \mathrm{ml} \mathrm{bFGF}$, and $30 \mathrm{~nm}$ TPA.

Immunoprecipitation and Western blot analyses. For immunoprecipitation, cultures were rinsed with PBS three times, and cells were scraped in PBS at $4^{\circ} \mathrm{C}$. The suspension was centrifuged at $14,000 \mathrm{rpm}$, and the resulting pellet was solubilized with a lysis buffer $(0.2 \%$ Triton X-100, 50 mu Tris- $\mathrm{HCl}, \mathrm{pH} 7.5,150 \mathrm{~mm} \mathrm{NaCl}, 1 \mathrm{~mm}$ EDTA, 2 mm phenylmethylsulfonyl fluoride, $5 \mathrm{mg} / \mathrm{ml}$ leupeptin, and $5 \mu \mathrm{g} / \mathrm{ml}$ pepstatin A) at $4^{\circ} \mathrm{C}$ for $1 \mathrm{hr}$. Aliquots ( $1 \mathrm{mg}$ of protein) of the lysate or the conditioned medium $(1 \mathrm{ml})$ were incubated with $5 \mu \mathrm{g}$ of the rabbit anti-neuregulin antibody and precipitated with $5 \mu$ l of protein A-Sepharose (Pharmacia, Uppsala, Sweden) at $4^{\circ} \mathrm{C}$.

After immunoprecipitation, the beads were washed three times with the lysis buffer. These samples were subjected to SDS-PAGE, followed by transfer to polyvinylidene difluoride membranes (Millipore, Barlborough, MA). Blots were blocked with $1 \%$ BSA and $1 \%$ normal horse serum in PBS for $30 \mathrm{~min}$ and then incubated with the goat antineuregulin- $\beta$ antibody at 1:200 dilution or with the rabbit anti-bovine GFAP antibody at 1:1000 dilution for $1 \mathrm{hr}$ at $4^{\circ} \mathrm{C}$. Immunoreactivity was detected with an avidin-biotin-peroxidase system (Vectastain ABC elite kit) using 4-chloro-1-naphthol as a color-developing reagent for $15 \mathrm{~min}$ at room temperature.

Immunocytochemistry of cultured astrocytes. Cultures to be immunostained were washed with PBS and fixed by immersion in $4 \%$ formaldehyde for $5 \mathrm{~min}$. The fixative was removed by washing three times with PBS. Cultures were first exposed to a blocking solution containing $1 \%$ normal horse serum and $0.01 \%$ Triton X-100 in PBS for $1 \mathrm{hr}$ at room temperature, followed by incubation with a mixture of the goat antibody against neuregulins at 1:200 dilution and the rabbit antibody against bovine GFAP at 1:1000 dilution in a blocking solution overnight at $4^{\circ} \mathrm{C}$. Biotin-linked anti-goat $\operatorname{IgG}$ was used as the secondary antibody. To visualize immunoreactivity for neuregulins and GFAP, Cy3-conjugated streptavidin and a fluorescein-conjugated antibody against rabbit IgG were used, respectively. The sections were observed under a fluorescence microscope (BX 60; Olympus, Tokyo, Japan). For display figures, merged color images were processed using Adobe Photoshop.

\section{RESULTS}

\section{Increase in the immunoreactivities for neuregulin and its putative receptors, ErbB2 and ErbB3, after brain injury}

In the intact rat brain, immunostainings with an anti-neuregulin antibody (Fig. $1 A-C$ ) and with an anti-ErbB2 antibody (Fig. $1 D-F)$ appeared to be localized in various areas of the cerebral cortex (Fig. $1 B, C, E, F$ ), hippocampus (Fig. 1A,D), and cholinergic nucleus in the diencephalon (data not shown), in agreement with other published reports (Chen et al., 1994; Pinkas-Kramarski et al., 1994; Eilam et al., 1998; Miller and Pitts, 2000). At the microscopic level, stainings for neuregulin and ErbB2 (Fig. 1C,F) were found primarily in neuronal cell bodies. However, ErbB3 was not detected on neuronal cells (data not shown).

The immunoreactivity for neuregulins (Fig. 2) and their receptors, ErbB2 (Fig. 3A-C,F) and ErbB3 (Fig. 3D,E, G), increased at traumatic sites, and the immunostained cells had the morpholog- 

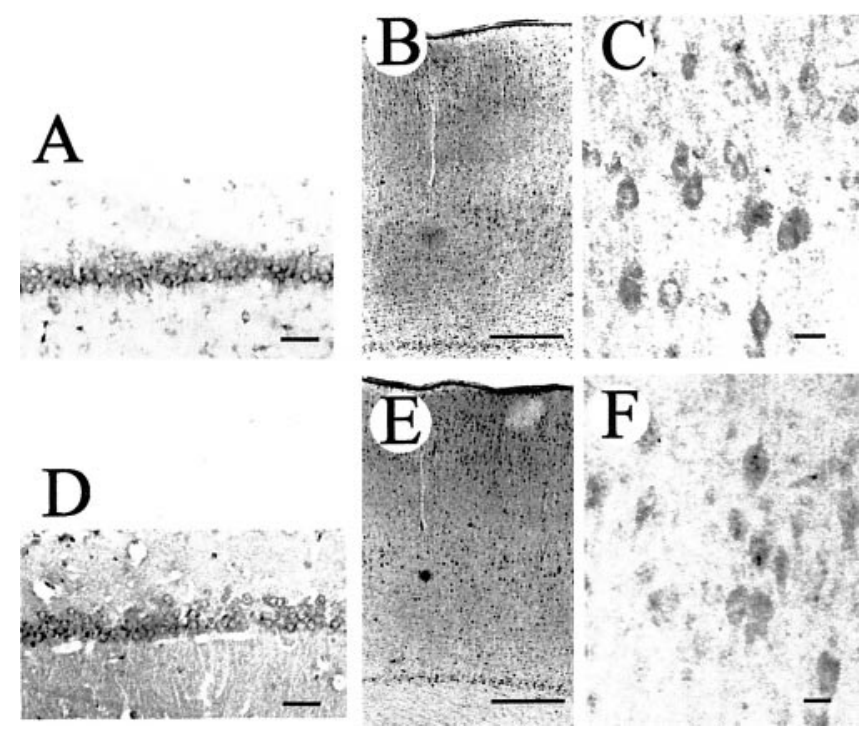

Figure 1. Immunohistochemical localization of neuregulin and ErbB2 in the cerebrum of an 8-week-old rat. An antibody against neuregulin- $\beta$ $(A-C)$ or an antibody against ErbB2 $(D-F)$ was used to stain paraformaldehyde-fixed thin sections. Immunolocalization of neuregulin $(A)$ and $\operatorname{ErbB} 2(D)$ in the CA1 area of the hippocampus is shown. The distribution of neuregulin $(B)$ and $\operatorname{ErbB} 2(E)$ in the cerebral cortex is also shown. Most neuregulin and ErbB2 immunoreactivities appear on neuronal cell surfaces. A higher magnification of immunostained sections shows the presence of neuregulin $(C)$ and $\operatorname{ErbB} 2(F)$ on cortical neuronal cells. Scale bars: $A, C, D, F, 50 \mu \mathrm{m} ; B, E, 500 \mu \mathrm{m}$.

ical features of reactive astrocytes (Figs. $2 C, 3 B, D$ ), which are known to proliferate around brain injuries. Preincubation of the antibodies with recombinant proteins reduced their immunoreactivities to a background level (Figs. $2 G, H, 3 B-E$ ). These results showed that the specificities of the antibodies used in this study were reliable.

To characterize the immunopositive cells further, we examined colocalization of GFAP with neuregulin or ErbB2 on cells around the injured site. A large population of GFAP-positive astrocytes showed neuregulin (Fig. $4 A-C$ ) and ErbB2 immunoreactivity (Fig. 4D-F) near the wound cave. In addition, we found that the ErbB3 (Fig. 4G) and ErbB2 (Fig. 4H) proteins were colocalized on astrocytes around the injured site (Fig. 4I).

Interestingly, we observed immunopositive cells stained with the anti-neuregulin antibody (Fig. $2 D-F$ ), the anti-ErbB2 antibody (Fig. $3 F$ ), and the anti-ErbB3 antibody (Fig. $3 G$ ) in a deep layer of the cortex along the white matter in the injured hemisphere. Staining of adjacent sections with the anti-GFAP antibody is shown in Figure 5. Although cells intensely stained for GFAP were found all over the cortex of the injured hemisphere (Fig. 5A-D), astrocytes with neuregulin, ErbB2, and ErbB3 immunoreactivities were found only near the injury site.

\section{Neuregulin expression by cultured astrocytes}

Neuregulin has been shown to play an important role in wound healing in the PNS (Carroll et al., 1997; Kopp et al., 1997) by enhancing cell migration and proliferation. The present results showing an increase in neuregulin expression after brain injury suggest that neuregulin also plays an important role in repair mechanisms in the CNS. Therefore, we investigated the possible regulatory mechanisms of neuregulin expression using cultured astrocytes as a model system.

We first examined whether cultured astrocytes expressed neu-
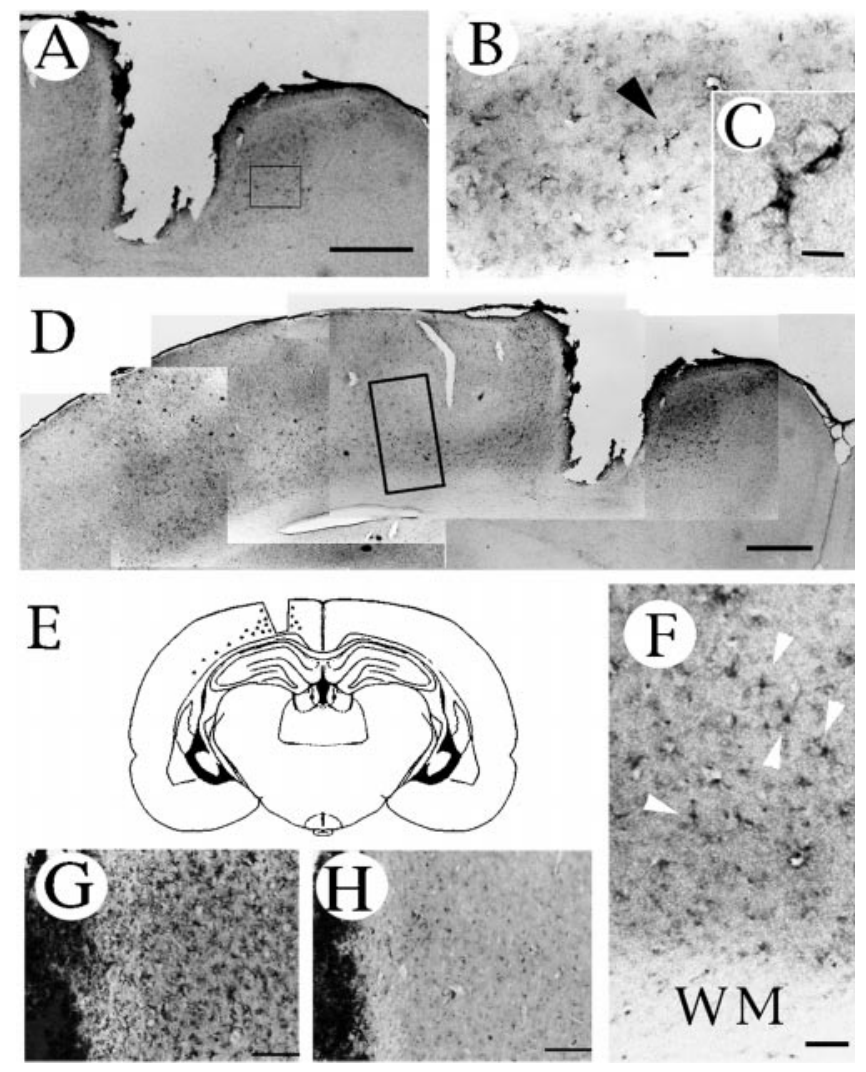

Figure 2. Immunohistochemical localization of neuregulin in the injured cerebral hemisphere. Highly neuregulin-immunoreactive cells are present near the wound $(A-C)$ and within a deep layer of the cortex $(D, F)$ close to the white matter. Higher magnifications of the boxed-in areas in $A$ and $D$ are displayed in $B$ and $F$, respectively. The arrowhead in $B$ indicates the more highly magnified cell shown in $C$. The arrowheads shown in $F$ indicate reactive astrocytic cells. $E$, A schematic representation of the sites that displayed immunoreactivity (shown by dots) in the coronal section. Sections were stained with an antibody pretreated with $(H)$ or without $(G)$ recombinant neuregulin to check the specificity of the antibody. All brain sections were prepared $4 \mathrm{~d}$ after trauma. $W M$, White matter. Scale bars: $A, D, 1 \mathrm{~mm} ; B, 50 \mu \mathrm{m} ; C, 10 \mu \mathrm{m} ; F-H, 400 \mu \mathrm{m}$.

regulins. We detected a $52 \mathrm{kDa}$ transmembrane form of neuregulin in cell lysates, and $\sim 35,32,30$, and $25 \mathrm{kDa}$ soluble forms in culture media (Fig. $6 A$ ) using a combination of immunoprecipitation and Western blot analysis. Although we used an antibody that reacts with both the $\alpha$ - and $\beta$-forms of the EGF-like domain of neuregulins for immunoprecipitation, we used an antibody that specifically recognizes $\beta$-form neuregulins for the Western blot. Thus, these immunopositive bands had the $\beta$-form of the EGFlike domain that was sufficient to activate some members of the EGF receptor family.

\section{Effects of intracellular cAMP-elevating reagents on neuregulin expression in vitro}

Recent studies have shown that many types of growth factors and cytokines are released from astrocytes after various treatments in vitro. Thus, candidate regulators of neuregulin expression were chosen on the basis of their previously published effects on the expression of the various neurotrophic factors in astrocyte cultures (Condorelli et al., 1994; Rudge et al., 1994). Because a transient increase in the intracellular cAMP level induces astrocyte differentiation, including morphological changes, increased GFAP expression, and increased phosphorylation of intermediate 


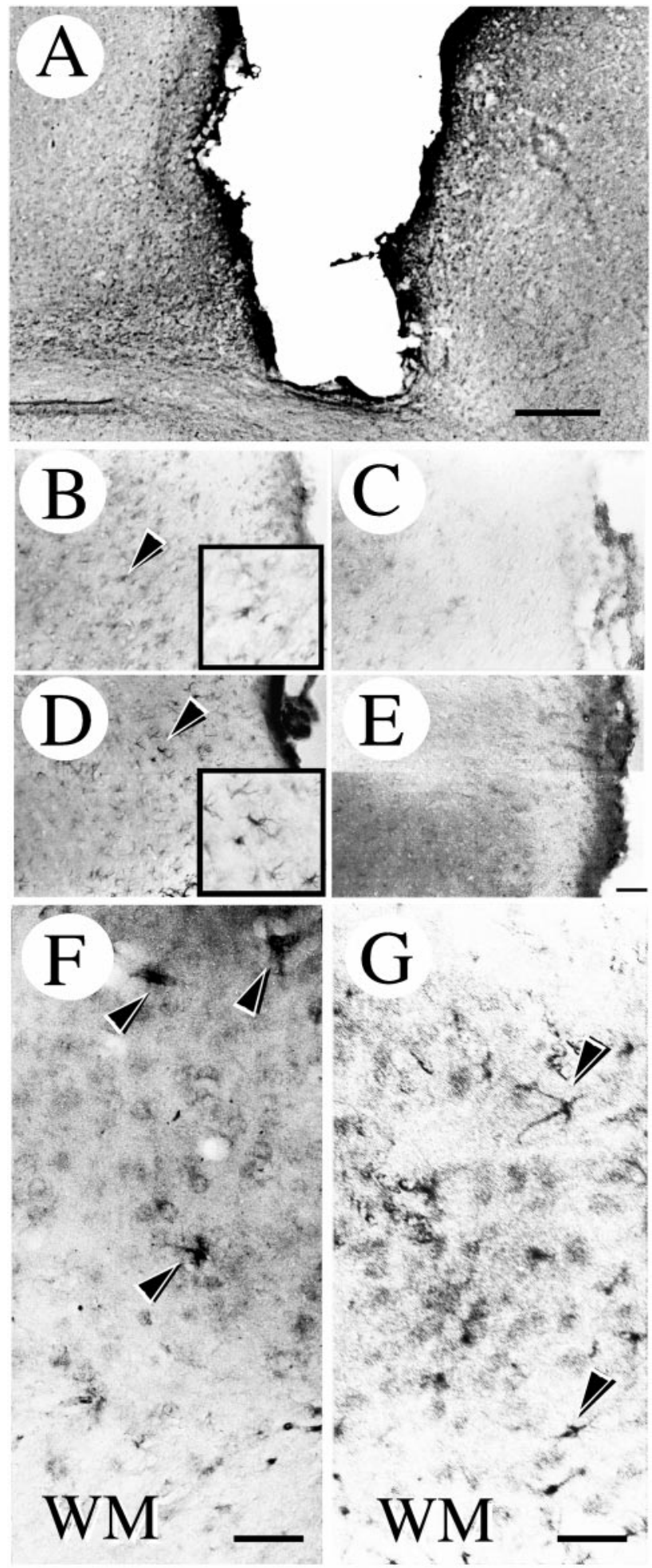

Figure 3. Immunohistochemical localization of ErbB2 and ErbB3 in the injured brain. $A$ shows anti-ErbB2 immunoreactive cells appearing near the wound. $B, D$, Higher magnification images of an area adjacent to the wound stained with anti-ErbB2 and anti-ErbB3 antibodies, respectively. The immunopositive cells indicated by the arrowheads are shown at a higher magnification in the box. These immunopositive cells were not observed in the sections stained with antibodies preabsorbed with the corresponding recombinant peptides $(C, E)$. In the deep layer of the injured cortex, $\operatorname{ErbB} 2(F)$ and $\operatorname{ErbB} 3(G)$ immunoreactivities were also detected. The black arrowheads shown in $F$ and $G$ indicate reactive astrocyte-like cells. $W M$, White matter. Scale bars: $A, 0.5 \mathrm{~mm} ; B-E$ (shown in $E$ ), $50 \mu \mathrm{m} ; F, G, 20 \mu \mathrm{m}$.
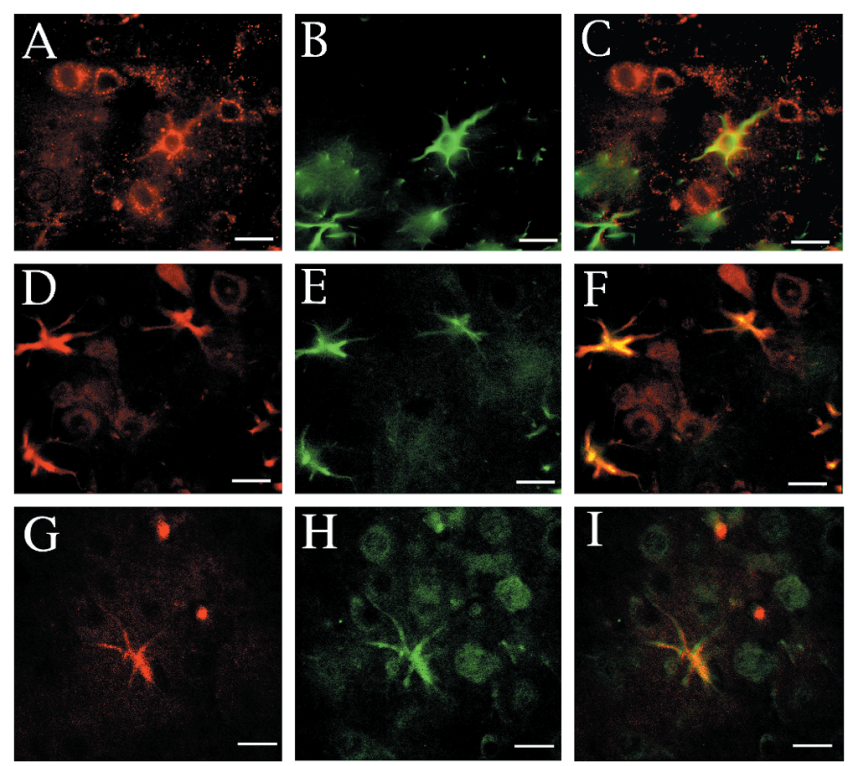

Figure 4. Double-label fluorescent localization of neuregulin with GFAP, ErbB2 with GFAP, and ErbB3 with ErbB2 in an injured cortex. $A$, Neuregulin immunoreactivity near the injured site. $B$, GFAP immunoreactivity in the same section of $A$. $C$, Superimposed image of $A$ and $B . D$, ErbB2 immunoreactivity near the injured site. $E$, GFAP immunoreactivity in the same section of $D . F$, Superimposed image of $D$ and $E$. $G$, ErbB3 immunoreactivity near the injured site. $H$, ErbB2 immunoreactivity in the same section of $G$. I, Superimposed image of $G$ and $H$. Scale bars, $10 \mu \mathrm{m}$.

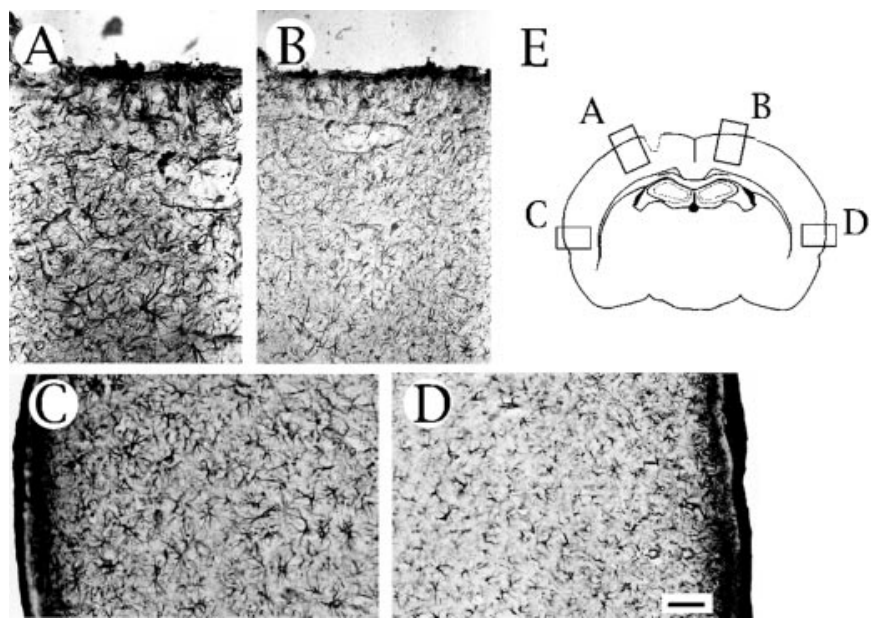

Figure 5. Immunohistochemical localization of an astrocytic differentiation marker, GFAP, in the injured brain. Intense immunoreactivity for GFAP is observed in the vicinity of $A$ and even in an area far from the injured site in the ipsilateral hemisphere $(C)$, but lower GFAP immunoreactivity was observed in the contralateral hemisphere $(B, D)$. $E$, Schematic representation of the areas used for the microscopic observation. Scale bar (in $D$ ), $50 \mu \mathrm{m}$.

filament proteins (Sensenbrenner et al., 1980; McCarthy et al., 1985), we selected cAMP-elevating reagents to investigate the regulation of neuregulin expression. Figure $6 B$ shows that forskolin and cAMP analogs enhanced the expression level of the 52 $\mathrm{kDa}$ neuregulin on astrocyte cell surfaces after a $3 \mathrm{hr}$ incubation. Soluble forms of neuregulins were not detected under these experimental conditions.

As shown in Figure 7, $A$ and $B$, treatment of astrocytes with forskolin for $3 \mathrm{hr}$ resulted in a dose-dependent enhancement of 


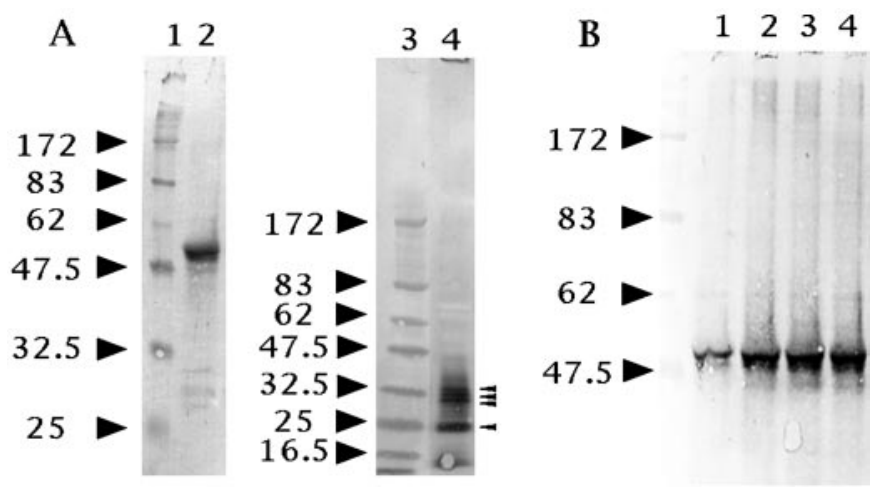

Figure 6. Western blot analysis of neuregulins in cell lysates and culture media. $A$ shows that astrocytes produced two neuregulin forms in vitro: a $52 \mathrm{kDa}$ membrane-spanning precursor in cell lysates (lane 2) and some soluble isoforms in culture media (lane 4). The small arrowheads in $A$ show neuregulin immunopositive bands with apparent molecular sizes of $35,32,30$, and $25 \mathrm{kDa}$, respectively. $B$, Forskolin and cAMP analogs enhanced the production of the $52 \mathrm{kDa}$ neuregulin precursor by cultured astrocytes for $3 \mathrm{hr}$ (lane 1, control; lane 2, $30 \mu \mathrm{M}$ forskolin; lane 3, $1 \mathrm{~mm}$ 8Br-cAMP; lane 4, $1 \mathrm{~mm} \mathrm{db}-\mathrm{cAMP})$. The positions of molecular mass markers (lanes 1 and 3 , in kilodaltons) are shown to the left of each panel.

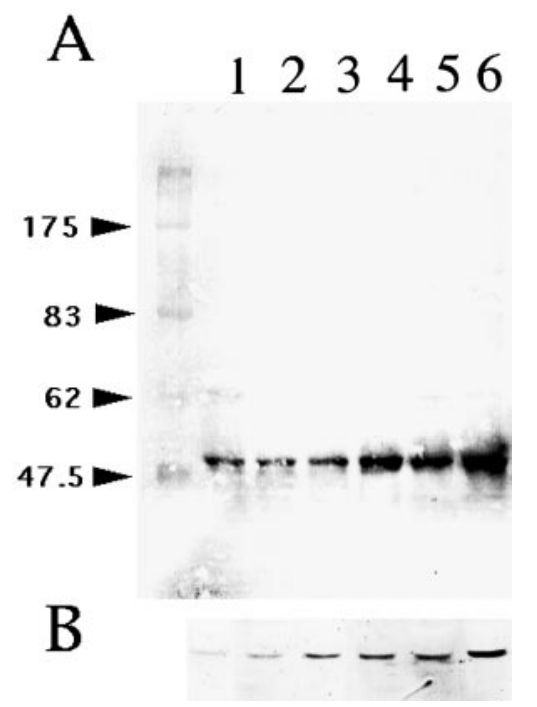

Figure 7. Western blot analysis of cultured astrocyte cell lysates treated with forskolin at various concentrations for $3 \mathrm{hr}$. Forskolin induced a dose-dependent increase in both the neuregulin $(A)$ and GFAP $(B)$ expressions by astrocytes. The concentrations of forskolin on $A$ and $B$ were as follows (in $\mu \mathrm{M}$ ): lane 1, 0; lane 2, 0.3; lane 3, 1; lane 4, 3; lane 5, 10; lane 6,30 , respectively. The positions of molecular mass markers (in kilodaltons) are shown to the left of $A$.

both neuregulin (Fig. 7A) and GFAP (Fig. 7B) expressions. No significant immunopositive bands were detectable in culture media under these experimental conditions.

To examine whether each astrocyte in culture expressed neuregulins, cultured astrocytes were stained with a mixture of antineuregulin and anti-GFAP antibodies. Most cells $(>95 \%)$ were immunopositive for GFAP (Fig. $8 A, D$ ), indicating that they were mostly astrocytes. However, GFAP-positive cells were not always immunopositive for neuregulins (Fig. 8B,E). The neuregulinpositive cells accounted for only $10 \%$ of the GFAP-positive cells and appeared to be stained with the anti-GFAP antibody more intensely than the neuregulin-negative cells (Fig. 8D, arrowhead). Treatment of astrocytes with forskolin resulted in a dramatic
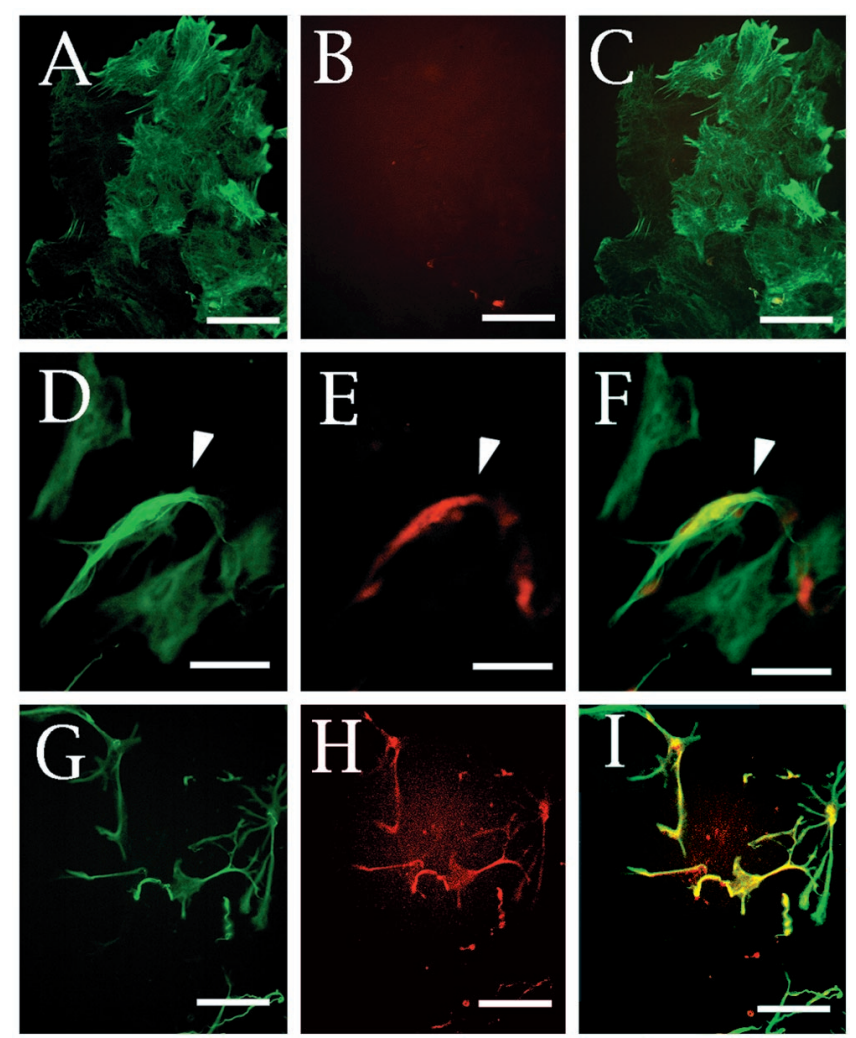

Figure 8. Immunofluorescence staining of neuregulin and GFAP on cultured astrocytes. Astrocytes cultured in DMEM supplemented with $10 \%$ FCS in the absence $(A-F)$ or presence $(G-I)$ of $3 \mu \mathrm{M}$ forskolin for $3 \mathrm{hr}$ are shown. The polygonal flat cells $(A-F)$ and the well characterized morphologically differentiated cells induced by forskolin administration $(G-I)$ were double-stained with anti-GFAP $(A, D, G)$ and anti-neuregulin $(B, E, H)$ antibodies. Anti-neuregulin and anti-GFAP antibodies were visualized with a biotinylated anti-goat IgG antibody and Cy3-labeled streptavidin (red) and fluorescein-labeled anti-rabbit ( green) IgG antibodies, respectively. The white arrowhead in $D-E$ indicates a neuregulinpositive cell in the control culture. The merged images of $A$ and $B, D$ and $E$, and $G$ and $H$ are also shown in $C, F$, and $I$, respectively. Scale bars, $10 \mu \mathrm{m}$.

morphological change in most cells (Fig. 8G) and an increase in the population of neuregulin-positive cells (Fig. $8 H$ ) to $20-30 \%$ of the total within $3 \mathrm{hr}$ in culture.

\section{Effects of growth factors and TPA on neuregulin expression and shedding in vitro}

Neuregulin was reported to be released from cell surfaces by PKC activation in cultured sensory neurons and neuregulin genetransfected CHO cells (Loeb et al., 1998). However, the effect of changes in PKC activity on neuregulin release from primary cultured astrocytes has not been studied. Therefore, we investigated the effects of TPA and growth factors on the shedding or release of neuregulin from astrocyte cell membranes into the culture media. Although astrocytes were treated with TPA or growth factors, the amount of neuregulins in the culture media were unchanged in our system (Fig. 9B, lanes 1-5). Compared with the normal culture conditions (Fig. 6A, lane 2), the amount of neuregulins with smaller molecular sizes was elevated in cell lysates (Fig. 9A, lane 1 ) under the low serum condition used in this experiment. In addition, the effects of TPA on the amounts of 65 , 60 , and $52 \mathrm{kDa}$ neuregulin isoforms in cell lysates were marked. The expression of 65 and $60 \mathrm{kDa}$ neuregulins was induced, but 
A
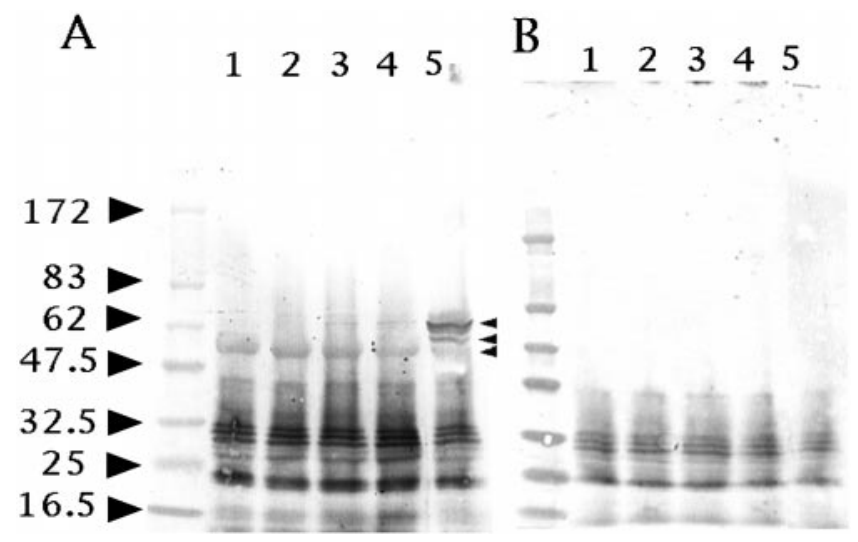

Figure 9. TPA and growth factors regulated neuregulin expression by cultured astrocytes. Cells incubated in DMEM containing low serum $(1 \%)$ received DMSO as a control (lane 1) or several growth factors (EGF, lane 2; bFGF, lane 3; PDGF, lane 4) and TPA (lane 5). The concentrations of these stimuli were: bFGF, $10 \mathrm{ng} / \mathrm{ml}$; EGF, $10 \mathrm{ng} / \mathrm{ml}$; PDGF, $10 \mathrm{ng} / \mathrm{ml}$; and TPA, $30 \mathrm{~nm}$. After $24 \mathrm{hr}$ of incubation, cell lysates and culture media were analyzed separately for neuregulin using an immunoblotting technique. $A$ shows a Western blot of cell lysates, and $B$ shows that of culture media. The small arrowheads in $A$ show neuregulinimmunopositive bands with apparent molecular sizes of 65,60 , and 52 $\mathrm{kDa}$, respectively. The positions of molecular mass markers (in kilodaltons) are shown to the left of each panel.

that of the $52 \mathrm{kDa}$ isoform was reduced after $24 \mathrm{hr}$ of TPA administration. Although EGF did not alter the expression of neuregulins (Fig. 9A, lane 2), bFGF and PDGF also induced the expression of the $65 \mathrm{kDa}$ neuregulin very weakly (Fig. 9A, lanes 3 , 4 ) in cell lysates.

\section{DISCUSSION}

\section{Expression of neuregulin, ErbB2, and ErbB3 in injured brains}

In the intact rat brain, immunostaining with an anti-neuregulin antibody appeared to be localized primarily in neuronal cell bodies in various areas, in agreement with other published reports showing neuregulin expression (Chen et al., 1994; PinkasKramarski et al., 1994; Eilam et al., 1998). We detected the colocalization of ErbB2 with neuregulin expressed on layer V cortical neurons in the rat brain (Fig. 1) in accordance with a recent report (Miller and Pitts, 2000).

In the injured brain, the increase in immunoreactivities for both neuregulin and ErbB receptors in the area surrounding lesions occurred because of the appearance of immunopositive cells with morphological features of reactive astrocytes (Figs. $2 C$, $3 B, D)$. Double-staining studies of ErbB2 and GFAP clearly showed their colocalization on astrocytes, as in a previous observation with human biopsy samples (Kristt and Yarden, 1996). In addition, neuregulin was also detected on GFAP-positive cells (Fig. 4). We also detected ErbB3 protein colocalized with the ErbB2 protein on astrocytes near the injury site (Fig. 4G-I). Although it is not known whether neuregulins have a promotive activity on the proliferation and migration of astrocytes, our results suggest that neuregulin may play a role in glial scar formation at an injured region in an autocrine and/or paracrine manner through the ErbB2-ErbB3 heterodimers. However, it is still unknown whether ErbB4, the other neuregulin receptor, is induced in astrocytes in the injured brain. In addition, the astrocytes near the injury would respond to other members of the neuregulin ligand family.
In a parallel study, we reported that the expression of neurocan, a neural chondroitin sulfate proteoglycan, was also enhanced by traumatic injury (Oohira et al., 1997). Injury to the adult CNS of higher vertebrates is rarely followed by axon regeneration. A major reason for this is the formation of an astrocytic scar that inhibits axon growth (Reier and Houle, 1988). The chondroitin sulfate proteoglycan produced by astrocytes is an inhibitory substrates for axon growth (Snow et al., 1990; Oohira et al., 1991). Thus, artificial growth control of astrocytes seems to be useful for the promotion of neuronal regeneration after trauma.

\section{Cultured astrocytes expressed neuregulins}

Neuregulin was originally reported as a $44 \mathrm{kDa}$ glycoprotein isolated from a Rat1-EJ cell line (Wen et al., 1992), and only a single neuregulin gene is localized in the human genome (OrrUrtreger et al., 1993). Alternative splicing was found to generate $>13$ neuregulin isoforms. Most of these included an Ig-like domain and a transmembrane domain, but some isoforms were produced as soluble forms without a transmembrane domain.

We detected two forms of neuregulin in primary astrocyte cultures using Western blot analysis: a $52 \mathrm{kDa}$ transmembrane form in cell lysates and some soluble forms in culture media (Fig. 6) with apparent molecular masses of 35, 32, 30, and $25 \mathrm{kDa}$. The $52 \mathrm{kDa}$ neuregulin isoform was reported previously from Western blots of the spinal cord (Carroll et al., 1997). Because there are many neuregulin splice variants, it could not be determined whether immunopositive bands in the culture media of astrocytes were synthesized as soluble forms or released from the cell surface by proteolytic processing, as is the case with other members of the EGF family such as TGF- $\alpha$ (Bringman et al., 1987; Gentry et al., 1987; Teixido et al., 1987), EGF (Mroczkowski et al., 1989), and heparin-binding EGF-like growth factor (HBEGF) (Izumi et al., 1998; Gechtman et al., 1999).

\section{Regulation of neuregulin expression by cultured rat cortical astrocytes}

It is well known that an increase in intracellular cAMP levels can induce several effects in astrocytes, such as dramatic morphological changes, increased GFAP expression, and increased phosphorylation of intermediate filament proteins. As shown in Figures $7 B$ and $8 G$, the increased GFAP content and morphological transformation induced by cAMP-elevating reagents were interpreted as a sign of differentiation or as a pathological reaction similar to the phenomena occurring in vivo during reactive gliosis. In this respect, it is interesting that elevated levels of neuregulin protein were detected on reactive astrocytes after injury to the rat brain.

In our model system using cultured cortical astrocytes, we observed a twofold to threefold increase in neuregulin protein levels after $3 \mathrm{hr}$ of incubation in the presence of forskolin (Fig. $7 A$ ). The $\mathrm{EC}_{50}$ of forskolin was found to be $\sim 3 \mu \mathrm{M}$ in the present study. We also observed a clear increase in the expression of neuregulin after treatment of primary astroglial cell cultures with $1 \mathrm{~mm}$ dB-cAMP or $1 \mathrm{~mm} 8 \mathrm{Br}-\mathrm{cAMP}$, as well as with $30 \mu \mathrm{M}$ forskolin (Fig. $6 B$ ). The enhancement because of forskolin treatment was inhibited by a 5 min pretreatment with $\left(2 \mathrm{~S}, 1^{\prime} \mathrm{R}, 2^{\prime} \mathrm{R}\right.$, $\left.3^{\prime} \mathrm{R}\right)$-2-2(2,3-dicarboxyclopropyl)glycine, an agonist of group II metabotropic glutamate receptors that is coupled with $\mathrm{G}_{\mathrm{i}}$ and negatively regulates adenylate cyclase (data not shown).

Only a minor population $(\sim 10 \%)$ of astrocytes showed neuregulin expression in our culture system. This was expected, because it is well known that cultured astrocytes are heteroge- 
neous in character. For example, the population of CNTFimmunopositive astrocytes was $10-15 \%$ of the total astrocytes derived from the hippocampus of newborn rat pups (Rudge et al., 1994), whereas the population of astrocytes without $\beta$-adrenergic receptors was $12 \%$ of the total GFAP-positive cells isolated from the adult rat brain (Shao and Sutin, 1992).

Some members of the EGF family, such as HB-EGF, were reported to be released from cell surfaces by a PKC-activated proteolytic enzyme (Izumi et al., 1998). In contrast, the proteolytic cleavage of neuregulin was independent of PKC activation, but the release of cleaved neuregulin from cell surfaces was promoted by the PKC signaling pathway in cultured sensory neurons and neuregulin gene-transfected CHO cells (Loeb et al., 1998). Because prolonged treatment with phorbol ester inactivates PKC activity (Wilkenson and Hallam, 1994), we treated astrocytes with TPA for a prolonged period to observe the effect of PKC inactivation on neuregulin synthesis and shedding. No difference in shedding was observed between the control and PKC-inactivated cultures, but the composition of the neuregulin isoforms in cell lysates changed dramatically after PKC inactivation. The $52 \mathrm{kDa}$ isoform appeared to be upregulated through the protein kinase A pathway (Fig. $6 B$ ) and downregulated by PKC inactivation (Fig. 9A). However, both the 65 and $60 \mathrm{kDa}$ isoforms were upregulated through PKC inactivation. These results suggest that the PKC signaling pathway enhances the processing of these two neuregulin isoforms or suppresses their expression. Because neuregulins can bind to heparan sulfate proteoglycans (Loeb et al., 1999), and molecules of a similar molecular size to neuregulins were seen in the culture media, these small neuregulins may be soluble in themselves but bound to heparan sulfate proteoglycans on the astrocyte cell surface under the culture conditions used.

\section{Possible roles of neuregulin in the injured CNS}

Increased neuregulin may play an important role in the cascade of cellular changes that occurs after focal brain injury. It has been shown that neuregulin promotes the survival, proliferation, and differentiation of various CNS cells such as astrocytes (PinkasKramarski et al., 1994), pro-oligodendrocytes (Canoll et al., 1996), oligodendrocytes (Shi et al., 1998), and neurons (BerminghamMcDonogh et al., 1996) in vitro. Although glial scars inhibit axonal regeneration, the increased concentration of neuregulin that we observed $4 \mathrm{~d}$ after brain injury may result in glial cell proliferation, leading to the repair of the damaged tissue. In addition, neuregulin may play an important role in supporting neuronal cell survival and regeneration in the recovery of neurological function after focal injury.

Interestingly, Cannella et al. (1998) demonstrated that recombinant neuregulin aided clinical recovery and repaired damaged myelin in a chronic relapsing experimental autoimmune encephalomyelitis mouse, a major model for a human demyelinating disease, multiple sclerosis (Marchionni et al., 1996; Cannella et al., 1998). After Wallerian degeneration, neuregulin and its receptor ErbB proteins are elevated on Schwann cells to promote their proliferation and remyelination (Carroll et al., 1997). It remains to be determined how the expression of neuregulins is regulated in astrocytes in vivo in relation to several temporal sequences of events that occur after trauma. If neuregulins in reactive astrocytes in the CNS are under regulation similar to that in vitro, it may be possible to use pharmacological intervention as a means to artificially augment neuregulin levels in the injured brain, and thus reduce the extent of neuronal degeneration after trauma.

\section{REFERENCES}

Bermingham-McDonogh O, McCabe KL, Reh TA (1996) Effects of GGF/neuregulins on neuronal survival and neurite outgrowth correlate with erbB2/neu expression in developing rat retina. Development 122:1427-1438.

Bringman TS, Lindquist PB, Derynck R (1987) Different transforming growth factor- $\alpha$ species are derived from a glycosylated and palmitoylated transmembrane precursor. Cell 48:429-440.

Cannella B, Hoban CJ, Gao YL, Garcia-Arenas R, Lawson D, Marchionni M, Gwynne D, Raine CS (1998) The neuregulin, glial growth factor 2, diminishes autoimmune demyelination and enhances remyelination in a chronic relapsing model for multiple sclerosis. Proc Natl Acad Sci USA 95:10100-10105.

Canoll PD, Musacchio JM, Hardy R, Reynolds R, Marchionni MA, Salzer JL (1996) GGF/neuregulin is a neuronal signal that promotes proliferation and survival and inhibits the differentiation of oligodendrocyte progenitors. Neuron 17:229-243.

Carroll SL, Miller ML, Frohnert PW, Kim SS, Corbett JA (1997) Expression of neuregulins and their putative receptors, ErbB2 and ErbB3, is induced during Wallerian degeneration. J Neurosci 17:1642-1659.

Chen MS, Bermingham-McDonogh O, Danehy Jr FT, Nolan C, Scherer SS, Lucas J, Gwynne D, Marchionni MA (1994) Expression of multiple neuregulin transcripts in postnatal rat brains. J Comp Neurol 349:389-400.

Condorelli DF, Dell'Albani P, Timmusk T, Belluardo N (1994) Expression of neurotrophins and their receptors in primary astroglial cultures: induction by cyclic AMP-elevating agents. J Neurochem 63:509-516.

Corfas G, Rosen KM, Aratake H, Krauss R, Fischbach GD (1995) Differential expression of ARIA isoforms in the rat brain. Neuron 14:103-115.

Eilam R, Pinkas-Kramarski R, Ratzkin BJ, Segal M, Yarden Y (1998) Activity-dependent regulation of Neu differentiation factor/neuregulin expression in rat brain. Proc Natl Acad Sci USA 95:1888-1893.

Falls DL, Rosen KM, Corfas G, Lane WS, Fischbach GD (1993) ARIA, a protein that stimulates acetylcholine receptor synthesis, is a member of the neu ligand family. Cell 72:801-815.

Finklestein SP, Apostolides PJ, Caday CG, Prosser J, Philips MF, Klagsbrun M (1988) Increased basic fibroblast growth factor (bFGF) immunoreactivity at the site of focal brain wounds. Brain Res 460:253-259.

Frautschy SA, Walicke PA, Baird A (1991) Localization of basic fibroblast growth factor and its mRNA after CNS injury. Brain Res 553:291-299.

Gechtman Z, Alonso JL, Raab G, Ingber DE, Klagsbrun M (1999) The shedding of membrane-anchored heparin-binding epidermal-like growth factor is regulated by the Raf/mitogen-activated protein kinase cascade and by cell adhesion and spreading. J Biol Chem 274:28828-28835.

Gentry LE, Twardzik DR, Lim GJ, Ranchalis JE, Lee DC (1987) Expression and characterization of transforming growth factor $\alpha$ precursor protein in transfected mammalian cells. Mol Cell Biol 75:1585-1591.

Higashiyama S, Horikawa M, Yamada K, Ichino N, Nakano N, Nakagawa T, Miyagawa J, Matsushita N, Nagatsu T, Taniguchi N, Ishiguro H (1997) A novel brain-derived member of the epidermal growth factor family that interacts with ErbB3 and ErbB4. J Biochem 122:675-680.

Ip NY, Wiegand SJ, Morse J, Rudge JS (1993) Injury-induced regulation of CNTF mRNA in the adult rat brain. Eur J Neurosci 5:25-33.

Izumi Y, Hirata M, Hasuwa H, Iwamoto R, Umata T, Miyado K, Tamai Y, Kurisaki T, Sehara-Fujisawa A, Ohno S, Mekada E (1998) A metalloprotease-disintegrin, MDC9/meltrin- $\gamma / \mathrm{ADAM} 9$ and PKC $\delta$ are involved in TPA-induced ectodomain shedding of membrane-anchored heparin-binding EGF-like growth factor. EMBO J 17:7260-7772.

Jensen AM, Chiu SY (1990) Fluorescence measurement of changes in intracellular calcium induced by excitatory amino acids in cultured cortical astrocytes. J Neurosci 10:1165-1175.

Jo SA, Zhu X, Marchionni MA, Burden SJ (1995) Neuregulins are concentrated at nerve-muscle synapses and activate ACh-receptor gene expression. Nature 373:158-161.

Kopp DM, Trachtenberg JT, Thompson WJ (1997) Glial growth factor rescues Schwann cells of mechanoreceptors from denervation-induced apoptosis. J Neurosci 17:6697-6706.

Kristt DA, Yarden Y (1996) Differences between phosphotyrosine accumulation and Neu/ErbB-2 receptor expression in astrocytic proliferative processes. Implications for glial oncogenesis. Cancer 78:1272-1283.

Lindholm D, Castren E, Kiefer R, Zafra F, Thoenen H (1992) Transforming growth factor- $\beta 1$ in the rat brain: increase after injury and inhibition of astrocyte proliferation. J Cell Biol 117:395-400.

Loeb JA, Susanto ET, Fischbach GD (1998) The neuregulin precursor proARIA is processed to ARIA after expression on the cell surface by a protein kinase C-enhanced mechanism. Mol Cell Neurosci 11:77-91.

Loeb JA, Khurana TS, Robbins JT, Yee AG, Fischbach GD (1999) Expression patterns of transmembrane and released forms of neuregu- 
lin during spinal cord and neuromuscular synapse development. Development 126:781-791.

Marchionni MA, Goodearl ADJ, Chen S, Bermingham-McDonogh O (1993) Glial growth factors are alternatively spliced erbB2 ligands expressed in the nervous system. Nature 362:312-318.

Marchionni MA, Kirk CJ, Isaacs IJ, Hoban CJ, Mahanthappa NK, Anton ES, Chen C, Wason F, Lawson D, Hamers FP, Canoll PD, Reynolds R, Cannella B, Meun D, Holt WF, Matthew WD, Chen LE, Gispen WH, Raine CS, Salzer JL, Gwynne DI (1996) Neuregulins as potential drugs for neurological disorders. Cold Spring Harb Symp Quant Biol 61:459-472.

McCarthy KD, Prime J, Harmon T, Pollenz R (1985) Receptormediated phosphorylation of astroglial intermediate filament proteins in cultured astroglia. J Neurochem 44:723-730.

Meyer D, Birchmeier C (1994) Distinct isoforms of neuregulin are expressed in mesenchymal and neuronal cells during mouse development. Proc Natl Acad Sci USA 91:1064-1068.

Miller MW, Pitts FA (2000) Neurotrophin receptors in the somatosensory cortex of the mature rat: co-localization of p 75 , trk, isoforms, and c-neu. Brain Res 852:355-366.

Miller S, Romano C, Cotman CW (1995) Growth factor upregulation of a phosphoinositide-coupled metabotropic glutamate receptor in cortical astrocytes. J Neurosci 15:6103-6109.

Mroczkowski B, Reich M, Chen K, Bell GI, Cohen S (1989) Recombinant human epidermal growth factor precursor is a glycosylated membrane protein with biological activity. Mol Cell Biol 9:2771-2278.

Oohira A, Matsui F, Katoh-Semba R (1991) Inhibitory effects of brain chondroitin sulfate proteoglycans on neurite outgrowth from PC12D cells. J Neurosci 11:822-827.

Oohira A, Ozeki J, Matsui F, Katoh-semba R, Keino H (1997) Transient expression of the juvenile form of neurocan after brain injury of the adult rat [abstract]. Glycoconj J 14:S145.

Orr-Urtreger A, Trakhtenbrot L, Ben-Levy R, Wen D, Rechavi G, Lonai P, Yarden Y (1993) Neural expression and chromosomal mapping of Neu differentiation factor to 8p12-p21. Proc Natl Acad Sci USA 90:1867-1871.

Ozaki M, Sasner M, Yano R, Lu HS, Buonanno A (1997) Neuregulin- $\beta$ induces expression of an NMDA-receptor subunit. Nature 390:691-694.

Peles E, Ben-Levy R, Tzahar E, Liu N, Wen D, Yarden Y (1993) Cell-type specific interaction of Neu differentiation factor (NDF/ heregulin) with Neu/HER-2 suggests complex ligand-receptor relationships. EMBO J 12:961-971.

Pinkas-Kramarski R, Eilam R, Spiegler O, Lavi S, Liu N, Chang D, Wen D, Schwartz M, Yarden Y (1994) Brain neurons and glial cells express Neu differentiation factor/heregulin: a survival factor for astrocytes. Proc Natl Acad Sci USA 91:9387-9391.

Reier PJ, Houle JD (1988) The glial scar: its bearing on axon elongation and transplantation approaches to CNS repair. In: Advances in neurology: functional recovery in neurological disease (Waxman SG, ed), pp 87-138. New York: Raven.

Rudge JS, Morrissey D, Lindsay RM, Panikowskyi EM (1994) Regulation of ciliary neurotrophic factor in cultured rat hippocampal astrocytes. Eur J Neurosci 6:218-229.

Rudge JS, Pasnikowski EM, Holst P, Lindsay RM (1995) Changes in neurotrophic factor expression and receptor activation following exposure of hippocampal neuron/astrocyte cocultures to kainic acid. J Neurosci 15:6856-6867.

Sandrock Jr AW, Goodearl AD, Yin QW, Chang D, Fischbach GD (1995) ARIA is concentrated in nerve terminals at neuromuscular junctions and at other synapses. J Neurosci 15:6124-6136.

Sensenbrenner M, Devilliers G, Bock E, Porte A (1980) Biochemical and ultrastructural studies of cultured rat astroglial cells: effect of brain extract and dibutyryl cyclic AMP on glial fibrillary acidic protein and glial filaments. Differentiation 17:51-61.

Shah NM, Groves AK, Anderson DJ (1996) Alternative neural crest cell fates are instructively promoted by TGF- $\beta$ superfamily members. Cell 85:331-343.

Shao Y, Sutin J (1992) Expression of adrenergic receptors in individual astrocytes and motor neurons isolated from rat brain. Glia 6:108-117.

Shi J, Marinovich A, Barres BA (1998) Purification and characterization of adult oligodendrocyte precursor cells from the rat optic nerve. J Neurosci 18:4627-4636.

Snow DM, Lemmon V, Carrino DA, Caplan AI, Silver J (1990) Sulfated proteoglycans in astroglial barriers inhibit neurite outgrowth in vitro. Exp Neurol 109:111-130.

Teixido J, Gilmore R, Lee DC, Massague J (1987) Integral membrane glycoprotein properties of the prohormone pro-transforming growth factor- $\alpha$. Nature 326:883-885.

Vartanian T, Corfas G, Li Y, Fischbach GD, Stefansson K (1994) A role for the acetylcholine receptor-inducing protein ARIA in oligodendrocyte development. Proc Natl Acad Sci USA 91:11626-11630.

Wen D, Peles E, Cupples R, Suggs SV, Bacus SS, Luo Y, Trail G, Hu S, Silbiger SM, Levy RB (1992) Neu differentiation factor: a transmembrane glycoprotein containing an EGF domain and an immunoglobulin homology unit. Cell 69:559-572.

Wilkenson SE, Hallam TJ (1994) Protein kinase C: is its pivotal role in cellular activation over-stated? Trends Pharmacol Sci 15:53-57.

Yang X, Kuo Y, Devay P, Yu C, Role L (1998) A cysteine-rich isoform of neuregulin controls the level of expression of neuronal nicotinic receptor channels during synaptogenesis. Neuron 20:225-270.

Yeh HJ, He YY, Xu J, Hsu CY, Deuel TF (1998) Upregulation of pleiotrophin gene expression in developing microvasculature, macrophages, and astrocytes after acute ischemic brain injury. J Neurosci 18:3699-3707. 